\title{
La planificación y la mentalidad de pequeños comerciantes*
}

Una corriente de crítica al proyecto de una nueva sociedad como es la construcción del socialismo, es la que concentra su atención en los aspectos de eficiencia, racionalidad de la gestión económica, productividad, asignación de recursos, etcétera. Esta corriente, a la que pertenece la obra en cuestión, sustenta implícita o explícitamente la tesi de que el socialismo se encuentra destinado a la ineficiencia por varias y simultáneas circunstancias. De ellas, las principales serían -para esta corriente de críticos- por una parte, el que el sistema socialista de precios no refleja necesidades ni restricciones en la disponibilidad de bienes y, por lo mismo, el método de asignación de recursos y de diseño de la gestión económica está incapacitado para garantizar la finalidad de producir lo mejor de la manera más económica posible (es decir, se desconocer las necesidades de los consumidores. y se desconocen las limitaciones de factores, excepto $e x$ post). Ello se debe, como se sabe, a que el sistema socialista de precios consiste en que ésto se fijan "propositivamente" en función de objetivos diversos y con diferentes criterios, en vez de dejarlos fluctuar, según el ideal capitalista, a fin de que las relaciones de mercado sean las que los determinen. Esta fijación se efectúa no en todos los bienes.

Una segunda esfera objeto de la crítica y a la que se supone fuente de obstáculos inconmovibles para lograr el ideal de la racionalidad socialista, consiste en el binomio formado por la manera de retribución y de estímulos a los trabajadores por una parte, y la capacidad individual de creatividad tecnológica, organizativa y de interés por la elevación de la productividad y la eficiencia. Estiman los críticos que el sistema de estímulos socialistas es incapaz de generar los impulsos individuales que se necesitan para lograr la máxima eficiencia. Es de suyo evidente que esta crítica se hace a partir del criterio de que el individualismo es el paradigma social.

Kaser y Zielinsky exponen en su obra un completísimo panorama de las formas por las que ha pasado la planificación en los países de Europa Oriental incluyendo, con frecuencia, referencias a la manera como operan los mismos aspectos en el caso

* M. Kaser y J. Zielinsky, la nUeva Planificación egonómica en europa oriental, Alianza Editorial, Madrid, 1971, pp. .... 
de la Unión Soviética. El rico material, con su detallada exposición de temas de primera importancia como son los de precios, salarios, estímulos, burocracia, compatibilidad de niveles de planificación, etcétera, lo convierten en un formidable resumen técnico de estos temas. Y este es precisamente su principal defecto, o sea que los autores pretenden mantener un punto de vista técnico sin supuestamente entrar en consideraciones políticas. Es decir, practican el más común de los errores propositivos de la crítica tortuosa y parcial al socialismo, que es el de aplicar un juicio político envuelto para ello en el ropaje de una supuesta objetividad técnica o científica que se autodenomina "apolítica". Con esta declaración de esterilidad política en el juicio de cuestiones que son esencialmente políticas, pretenden ocultar su feroz posición conservadora.

Para calificar de esta manera a los dilectos autores Kaser y Zielinsky, es suficiente considerar que el análisis y la crítica la efectúan en relación a cuestiones económicas de la planificación, a fin de desvincularlas de los objetivos sociales de la misma, atribuyendo con la usual deformación del pequeño comerciante, fines exclusivamente económicos a la gestión económico-social. De esta manera se esgrime el criterio de empresario para enjuiciar a una economía socialista, lo que conduce a convenientes errores que los autores critican con una virtuosa objetividad desde el tranquilo recinto de St. Anthonys College, en Oxford.

Desde un principio se debe aceptar que la apreciación de las características de la planificación socialista se necesita efectuar no con criterios de maximización de utilidades privadas a partir de una información dada de precios -o de criterios aportados por las débiles adaptaciones metodológicas que se aplican, para evaluar inversiones públicas-, sino de los objetivos del socialismo. Y dentro de estos objetivos jamás se podrán encontrar los de la producción por sí misma o la eficiencia por el amor a ella, sino cada aspecto como parte formativa del ser humano, como condición para su existencia satisfactoria, como medio de procurar un proceso de desenajenación que es largo por necesidad $y$ -aquí sí- con numerosos errores que deben ser objeto de corrección. Pero planteado el problema en estos términos las cuestiones fundamentales que han sido objeto de crítica cobran un perfil completamente diferente.

En lo que se refiere a la cuestión de los sistemas de precios se establece la noción central de que la vigencia de la ley de valor es el criterio determinante y que dichos precios se deberán modificar de acuerdo con objetivos específicos de corto y largó plazo. Sin embargo, el cambio de valor a precio ha sido tema de un largo debate todavía no terminado y que ha influido en la elección de niveles de precios en función de criterios extramercan- tiles. La razón de este procedimiento es precisamente el que se reconocen dos cuestiones centrales para el socialismo: una, la que se refiere a la eliminación ya sea gradual o radicalmente, según el estilo de cada país, de las fuentes de resistencias y tendencias antisocialistas, las que principalmente se localizan en los estratos llamados "pequeño burgueses". Entre estas tendencias resaltan las que surgen por la práctica del comercio privado de la pequeña propiedad agrícola. Por ello es que la eliminación del mercado como centro de intercambio autónomo es un objetivo político de principal importancia, no sólo para impedir el resurgimiento del pequeño y el gran comerciante privados - que con mayor o menor dificultad podían ser sustituidos por el aparato estatal de distribuciónsino también el surgimiento de sentimientos pequeños burgueses que son por naturaleza altamente nocivos por su intenso efecto regresivo sobre grandes masas, ya de aspirantes a comerciantes, ya de compradores que acuden a practicar ese modo de intercambio. Que existen países socialistas en los que, en diverso grado, hay este tipo de intercambio, sólo demuestra la permanente necesidad de revisar los postulados y las maneras de formar una nueva sociedad a partir de seres humanos deformados por siglos de práctica de la cultura capitalista y mercantilista. $Y$ de esta deformación no tienen por qué estar completamente libres ni siquiera los dirigentes más preclaros de ningún nivel, aún cuando sí deben estar concientes de ello y, en ocasiones a pesar de sí mismos, vigilar que se corrijan dichas deformaciones. ¿Qué todo es difícil de lograr y que existen graves fallas? Sin duda, y además de errores importantes que se cometen, esto es fuente de importantes conflictos. Pero también es necesario recordar que el conflicto, como parte de la dialéctica social, no tiene por qué desaparecer en el socialismo. Lo que cambia es el contenido, dinámica y solución del conflicto.

En el contexto anterior, lo que resul'a procedente no es la infantil crítica de que no rigen los precios de un mercado libre $y$ que por ello surgen ineficiencias según los criterios que idealmente esgrime el propietario de empresas capitalistas. La crítica acertada en todo caso consistiría en reclamar la aplicación de diversas hipótesis en torno a la forma y modalidades de operación actual de la ley del valor en diversas economías socialistas; en torno a la manera cómo el valor de uso influye en la definición de lo "socialmente necesario" del trabajo aplicado a la producción; en torno a la transformación de valor en precios; en torno al efecto del lapso que existe entre inversión, gestión económica y precio, etcétera.

Lo anterior puede sugerir que comparto la idea implícita en los autores del libro de que la gestión socialista es por naturaleza ineficiente. No es así. Greo que 
en el socialismo se pone en evidencia la necesidad de racionalizar la gestión económica y regular el sistema de precios con criterios sociales, y que en la medida que esto se plantea representa un avance en la posibilidad para lograrlo. En el sistema capitalista ni siquiera se plantea el problema y a la ignorancia del mismo se le atribuyen virtudes científicas. Así, a precios relativos que pueden significar cualquier cosa, inclusive escaseces re lativas, se les añade un aparato arcaico de análisis para hacer pobres gestos de imitación o caricaturas de la idea de lo "científico", para tranquilidad del operador y de su público. A la acusación de que los socialistas no están efectuando juegos de marioneta de este tipo se le llama juicio objetivo y se clama por la irracionalidad de todo sistema no capitalista.

Lo mismo sucede en el caso de las retribuciones, salarios, y de la participación de los obreros en el consumo, entre otras cuestiones. El sentido de transición que tienen las sociedades socialistas, primero hacia estadios más avanzados de esta forma de organización y después hacia el comunismo, supone un cambio gradual de la participación en el consumo, pero también el que la manera como tiene lugar dicho cambio sea la apropiada para que el ser humano se transforme con mayor rapidez. Es decir, la velocidad y modalidades de esta modificación tienen una relación directa con los objetivos de de- senajenación del ser humano, con los de la asignación apropiada del producto para satisfacer las necesidades de consumo y de formación de capital, entre otros. La finalidad última que se plantea es la de que los seres humanos se humanicen al grado de que, con plena conciencia de su papel social y debido estímulo que significa la colaboración social, cada quien produzca creativamente. En ese estadio de evolución los estímulos sociales serán ampliamente suficientes para el avance en materia de eficiencia, productividad, etcétera, pero para ello es indispensable alcanzar un grado de conciencia todavía inexistente. En el periodo de transición resulta necesario crear las condiciones individuales y sociales para que vaya produciéndose el cambio hacia el estadio siguiente, al mismo tiempo que se atienden otras esferas indispensables para este mismo objetivo, como es disponer de un creciente número de satisfactores materiales que permita eliminar gradualmente la enajenación en el consumo. Además, no se puede olvidar el contexto mundia en el que se encuentran ubicadas las sociedades socialistas, y las necesidades que impone en la colaboración internacional o por la permanente amenaza externa

Las condiciones antes mencionadas, junto con otras más, imponen la tarea de mantener un sutil equilibrio entre logar una elevada producción, asignar recursos suficientes a la formación de capital - y por lo tanto afec- tar los salarios para eliminar correlativamente el consumo-, y lograr la gradual transformación del ser humano. De esta manera se debe conciliar la tendencia hacia aplicar un sistema de incentivos para estimular una mayor producción, con la necesidad de eliminar gradualmente los estímulos materiales a fin de ir reduciendo la incidencia de las maneras de actuar de los individuos que alimenten factores regresivos de enajenación. En éste como en todos los demás ámbitos de la vida socialista es indudable y previsible el surgimiento de errores, la necesidad de experimentar y de mejorar permanentemente los métodos de acción social y de politización. Todo ello pone en evidencia la dinámica de la sociedad socialista, las condiciones y conflictos que surgen de toda evolución, pero también el que en diversa medida se avanza hacia los fines postulados por el socialismo.

En cambio, el asumir que las evidencias de estos complejos procesos de ajuste, que se antojan lentos, son demostraciones de la falla del socialismo y de su inaplicabilidad, es un indicio de serias deformaciones en la concepción social del crítico. Los autores Kaser y Zielinsky, dentro de la amplia información que manejan, reiteran la nostalgia por los métodos donde el interés material, incluyendo la paticipación en utilidades, pueden impulsar el interés individualista del trabajador a elevar su productividad. Esto puede ser cierto y efectivo desde este ángulo productivo, pero también puede significar una regresión en los objetivos socialistas, que represente un costo social mucho mayor que las ventajas que puede representar el alcanzar niveles de producción más altos. Además deben considerarse las circunstancias mundiales que determinan que en las sociedades, todos los asuntos, incluyendo las variantes en la manera de distribuir el ingreso y de organizar la gestión económica, cobran importancia doctrinaria.

El camino hacia el socialismo es largo y se cometen grandes equivocaciones y desviaciones de elevado costo social, todo lo cual es aprovechado por los defensores del capitalismo para proclamar su invalidez, muchas veces reclamando qué no alcanza instantáneamente el ídeal de largo plazo. Es decir, uno de los argumentos que se utiliza para objetar al socialismo es que no es todavía socialismo. Sin embargo, ese camino largo que es motivo de objeción por parte de los críticos temerosos de sus pequeños intereses, corresponde al gran parto actual de la humanidad, y como todo parto no tiene retorno posible. Y no sólo está planteada la transformación en un grupo de países sino en el mundo entero, que es precisamente lo que preocupa a los críticos. SERGIO DE LA PEÑA. 